\title{
MICROPLASTICS AS VECTOR FOR PERSISTENT ORGANIC POLLUTANTS IN URBAN EFFLUENTS: THE ROLE OF POLYCHLORINATED BIPHENYLS
}

\author{
JAVIER BAYO ${ }^{1}$, MARTA GUILLÉN ${ }^{1}$, SONIA OLMOS ${ }^{1}$, PILAR JIMÉNEZ², \\ ERNESTO SÁNCHEZ ${ }^{3}$ \& MARÍA J. ROCA ${ }^{4}$ \\ ${ }^{1}$ Department of Chemical and Environmental Engineering, Technical University of Cartagena, Spain. \\ ${ }^{2}$ Department of Civil Engineering, Technical University of Cartagena, Spain. \\ ${ }^{3}$ Head Manager WWTP "Cabezo Beaza", Hidrogea, Spain. \\ ${ }^{4}$ Support Service for Technological Research, Technical University of Cartagena, Spain.
}

\begin{abstract}
The presence of microplastics in the environment is considered a global threat, not only for the physical damage induced to the organisms that ingest them and leachability of their constituent, but also as a potential carrier of organic and inorganic contaminants, with an interaction poorly described. Microbeads collected from four facial cleansers, with a well-known polymeric and additive composition, were used as an indicator for the sorption of polychlorinated biphenyls (PCBs) in treated urban effluents, in order to study the behavior of microplastics versus these persistent organic pollutants in water. A stock standard solution (EPA 525, 525.1 PCB mix) was used for this purpose, being a certified material produced in accordance with ISO Guide 34:2009 and ISO/IEC 17025:2005. It consists of a mixture of eight congeners: PCB1, PCB5, PCB31, PCB47, PCB91, PCB154, PCB171 and PCB200 in n-hexane $(500 \mu \mathrm{g} / \mathrm{ml}$ of each component). Sorption experiments were carried out in batch mode, previously in bi-distilled water, and finally in treated urban effluents. PCB congeners retained by microplastics and remaining in water were further analyzed by means of gas chromatography, using a protocol previously described with an initial column temperature of $70^{\circ} \mathrm{C}$ and a ramp of $10^{\circ} \mathrm{C} / \mathrm{min}$ up to $150^{\circ} \mathrm{C}, 3^{\circ} \mathrm{C} / \mathrm{min}$ up to $200^{\circ} \mathrm{C}$, and $8^{\circ} \mathrm{C} / \mathrm{min}$ to a final temperature of $280^{\circ} \mathrm{C}$. The sorption process proved to be reliable and repeatable both for samples in bi-distilled water and treated urban effluents, showing different interactions between the organic pollutants and the microplastics. PCB congeners with a low-molecular weight proved to be preferentially sorbed by an oxidized polyethylene included in one of the microbeads, although the maximum amount for total PCB sorption was for the facial cleanser with $\mathrm{TiO}_{2}$ in its composition.

Keywords: microbead, microplastic, PCB, persistent organic pollutant, sorption, urban effluent.
\end{abstract}

\section{INTRODUCTION}

The global annual production of plastics was around 322 million tonnes for 2015, with approximately an $18 \%$ of them produced in Europe, where $70 \%$ of the demand is concentrated in six countries: Germany $(24.6 \%)$, Italy (14.3\%), France $(9.6 \%)$, Spain $(7.7 \%)$, UK (7.5\%), and Poland (6.3\%) [1]. Plastic wastes buried in landfills have decreased a $38 \%$ from 2006 on, but their energy recovery processes and, especially, their recycling still need to be increased in a future as a key resource for circular economy. Meanwhile, and due to their high durability in the environment, plastics accumulate at an uncontrolled rate, being one of the most persistent pollutants all over the world [2].

The fragmentation of large plastic debris into smaller ones takes place in the environment, due to physical, biological and chemical mechanisms, being chemical and mechanical weathering the most important ones [3], originating the so-called 'secondary microplastics'. The term 'microplastic' is used for plastics smaller than $5 \mathrm{~mm}$, classified as 'large microplastics', between 1 and $5 \mathrm{~mm}$, and 'small microplastics', smaller than $1 \mathrm{~mm}$, being defined as 'nanoplastics' when the diameter is smaller than $1 \mu \mathrm{m}$ [4]. Besides, 'primary microplastics', sometimes called nurdles, resin beads or microbeads, are defined as plastics manufactured to 
have a microscopic size [3] and widely used for different purposes in industry, personal care products or in medicine. These pollutants may be released from wastewater treatment plants, through the treated effluent or the sludge [5], reaching the environment and accumulating.

The sorptive function of plastic pellets, mainly made of polyethylene (PE) or polypropylene (PP), for both inorganic [6] and organic pollutants [7] has also been considered of concern, because a global transport of microplastics in the environment may act as a vehicle for all these pollutants. In this study, microbeads collected from four facial cleanser scrubs soap-based, with a well-known polymeric and additive composition, were tested for polychlorinated biphenyls (PCB) sorption in water effluents from the wastewater treatment plant (WWTP) 'Cabezo Beaza', located in Cartagena (Murcia, Spain). Previous analyses were carried out in bi-distilled water [8], in order to undertake an initial theoretical study to gain knowledge about the sorption behavior of these micropollutants.

PCBs are a mixture of up to 209 PCB congeners with, at least, half of them still in use in older electrical equipments, especially transformers, hydraulic fluids, carbonless carbon paper, compressors or in storage, with the potential to be released into the environment [9]. Although initially, all PCB congeners were regarded as toxic, in vivo studies conducted with rodents in the 1970s and 1980s found that the toxicity varied greatly according to the location and number of chlorine atoms [10]. This paper presents the results of PCB sorption on microbeads extracted from four facial cleansers in treated urban effluents from 'Cabezo Beaza', a wastewater treatment plant located in Cartagena (Spain). A stock standard solution (EPA 525, 525.1 PCB mix), consisting of a mixture of eight congeners: PCB1, PCB5, PCB31, PCB47, PCB91, PCB154, PCB171, and PCB200 in n-hexane, was used for this purpose.

\section{MATERIALS AND METHODS}

\subsection{Extraction of microbeads from facial cleansers}

Microbeads included in four commercial facial cleansers, named as (MP: Microplastic) MP-A, MP-B, MP-C, and MP-D, and made of polyethylene, were used to test PCB sorption in treated urban effluents. They were selected attending their prevalence in major Spanish supermarkets, with a wide range of prices, from 39.67 up to $106.75 € / 1$, and aimed at both male and female audience. The extraction of microbeads has been previously published elsewhere [8]. Basically, it consists of a hot-water extraction in a $2 \mathrm{~L}$ beaker $(60 \mathrm{rpm} / 30 \mathrm{~min})$ with a final sieving step through a No. 270 mesh (Sigma-Aldrich, Saint Louis, MO, USA). Samples were dried at $60^{\circ} \mathrm{C}$ for $24 \mathrm{~h}$ until a constant weight in a precision balance, and stored in sterilized glass vials into a desiccator for later use, in order to avoid moisture adsorption.

\subsection{Treated urban effluents}

Treated urban effluents (TUE) were collected from the urban wastewater treatment plant (WWTP) 'Cabezo Beaza' located in Cartagena (Spain). It consists of a conventional system with a primary treatment and two activated sludge reactors, serving about 210,000 equivalent inhabitants and fed by about $35,000 \mathrm{~m}^{3}$ a day. The biological reactor consists of an anoxic tank for pre-denitrification followed by a facultative tank, both completely mixed and with a volume of $2025 \mathrm{~m}^{3}$ each one (there are two of them), ahead of the plug-flow aerobic reactor with a total net volume of $12150 \mathrm{~m}^{3}$, and internal recirculation of aerated mixed liquor to the anoxic and facultative zones. Prior to batch experiments, wastewater samples 
were filtered using a $1.20 \mu \mathrm{m}$ glass fiber filter (Millipore, Bedford, MA, USA) to eliminate suspended solids.

\subsection{Batch sorption experiments and PCB extraction}

A stock standard solution (EPA 525, 525.1 PCB mix, Sigma Aldrich, Saint Louis, MO, USA) was used for the sorption experiments, being a certified material produced in accordance with ISO Guide 34:2009 and ISO/IEC 17025:2005. It consists of a mixture of eight congeners: PCB1, PCB5, PCB31, PCB47, PCB91, PCB154, PCB171, and PCB200 in $n$-hexane (500 $\mu \mathrm{g} /$ $\mathrm{ml}$ of each component). Systematic numbering of $\mathrm{CB}$ congeners was carried out according to Ballschmiter and Zell (BZ congener number) [11].

An intermediate stock congener $50 \mu \mathrm{g} / \mathrm{ml}$ solution was prepared in acetone and stored at $-18^{\circ} \mathrm{C}$. Sorption experiments were carried out in batch mode in treated urban effluents artificially spiked with a standard working congener mixture to a final $100 \mu \mathrm{g} / \mathrm{l}$ concentration. For this purpose, $5 \mathrm{mg}$ of each microbead type was shaken with $10 \mathrm{ml}$ of the PCB working solution in a 20-ml glass vessel tightly closed with magnetic screw cap with silicone/PTFE septa. Different experiments were previously carried out in order to assess the best experimental conditions, according to time extraction, salt addition or sample volume.

After the batch sorption experiment, samples were filtered using filter paper (Albet ${ }^{\circledR}$ LabScience), and microbeads were washed with ultrapure water and completely dried up before analysis by gas chromatography (GC). For the extraction of remaining PCB congeners in TUE, a stir bar sorptive extraction (SBSE) procedure (Twister ${ }^{\mathrm{TM}}$ ) was used. Stir bars of 10 $\mathrm{mm}$ in length with an external polydimethylsiloxane (PDMS) coating of $0.5 \mathrm{~mm}$ thickness were purchased from Gerstel (Mülheiman der Ruhr, Germany). Stirring was performed on a Nahita model 685/1 shaker for $24 \mathrm{~h}$.

\subsection{Gas chromatography}

PCB congeners were analyzed by GC (Agilent $6890 \mathrm{~N}$ ) coupled to a 5975N inert XL mass selective detector (GC/MS) (Agilent Technologies, Palo Alto, CA, USA) equipped with a thermal desorption unit (TDU), a cooled injector system (CIS 4) with programmable temperature vaporization (PTV) and a GERSTEL ${ }^{\circledR}$ MultiPurpose sampler (Gerstel, Mülheim an der Ruhr, Germany). GC analyses were carried out in a HP-5MS UI capillary column $(30 \mathrm{~m} \times 0.25 \mathrm{~mm}$, $0.25 \mu \mathrm{m})$ in constant pressure mode. The initial column temperature was $70^{\circ} \mathrm{C}(2 \mathrm{~min})$. Thereafter, the temperature was firstly ramped at $10^{\circ} \mathrm{C} / \mathrm{min}$ to $150^{\circ} \mathrm{C}, 3^{\circ} \mathrm{C} / \mathrm{min}$ to $200^{\circ} \mathrm{C}$ and finally ramped at $8^{\circ} \mathrm{C} / \mathrm{min}$ to a final temperature of $280^{\circ} \mathrm{C}(10 \mathrm{~min})$. Chromatographic-grade helium was used as the carrier gas, and injection was done in solvent vent mode.

Microbead and Twister ${ }^{\mathrm{TM}}$ were analyzed using thermal desorption in combination with GC-MS in Scan mode. They were thermally desorbed by programming the TDU from $40^{\circ} \mathrm{C}$ (1 min) to $250^{\circ} \mathrm{C}$ at $60^{\circ} \mathrm{C} / \mathrm{min}(7 \mathrm{~min})$. After thermal desorption, the volatile organic $\mathrm{PCB}$ congeners were cryofocused in the CIS4 PTV injector at $-100^{\circ} \mathrm{C}$ using liquid $\mathrm{N}_{2}$ with a equilibration time of $0.10 \mathrm{~min}$. After cryofocusing was completed, the volatiles were transferred into the capillary column by heating the CIS4 PTV inlet at a rate of $10^{\circ} \mathrm{C} / \mathrm{s}$ to $250^{\circ} \mathrm{C}(7 \mathrm{~min})$. The optimization of PCB congeners' retention time was carried out by injecting $1 \mu \mathrm{l}$ of 100 ppb PCB solution into a Twister ${ }^{\mathrm{TM}}$. The transfer temperature was $300^{\circ} \mathrm{C}$ in splitless injection mode. Mass spectra were acquired over the scan range of $\mathrm{m} / \mathrm{z} 30-450$ and measurements were carried out with electron-bombardment ion (EI) source with $70 \mathrm{eV}$ of electron energy. 
The transfer line, source, and quadrupole temperatures were set at 280,230 and $150^{\circ} \mathrm{C}$, respectively. The chromatograms and mass spectra were evaluated using the ChemStation software G1701EA, version E.02.02 SP1 (Agilent Technologies, Inc.), and quantification was performed in Scan mode, using target ions for each PCB.

\section{RESULTS AND DISCUSSION}

\subsection{Gas chromatographic retention times of PCB congeners}

Table 1 shows a description of each PCB congener included in the mix; although each compound is defined by different major peaks, the following ones in the mass spectrum were used as the most intense ions for quantification: PCB1 (ion 188), PCB5 (ion 222), PCB31 (ion 256), PCB47 (ion 292), PCB91 (ion 326), PCB154 (ion 360), PCB171 (ion 394), and PCB200 (ion 430).

Chromatographic peak identification was made by library matching using the Standard Reference Database Wiley 2010NIST/EPA/NIH Mass Spectral Database (NIST 11). The retention times were: $10.86 \mathrm{~s}$ for PCB1, $14.50 \mathrm{~s}$ for PCB5, $17.71 \mathrm{~s}$ for PCB31, $20.46 \mathrm{~s}$ for PCB47, $23.27 \mathrm{~s}$ for PCB91, $26.77 \mathrm{~s}$ for PCB154, $31.79 \mathrm{~s}$ for PCB171, and $32.02 \mathrm{~s}$ for PCB200, as depicted in Figure 1.

\subsection{Optimization of sample extraction procedure}

Different parameters were tested in order to a better SBSE procedure, always trying to avoid an excessive manipulation of the sample during the extraction step.

Because the ionic strength has been reported as one of the most important parameters affecting the SBSE procedure [13], experiments with $1 \mathrm{~g} \mathrm{NaCl}$ were carried, although no statistically significant differences could be observed comparing with the extraction

Table 1: IUPAC names, number of Chemical Abstracts Service and major ions of 8 PCB congeners.

\begin{tabular}{|c|c|c|c|c|}
\hline $\begin{array}{l}\text { BZ conge- } \\
\text { ner number }\end{array}$ & IUPAC name & CAS no. & $\begin{array}{l}\log \\
K_{o w} *\end{array}$ & Selected ions $(m / z)^{\uparrow}$ \\
\hline 1 & 2-Chlorobiphenyl & $2051-60-7$ & 4.46 & $152 ; 153 ; \mathbf{1 8 8} ; 190$ \\
\hline 5 & 2,3-Dichlorobiphenyl & $16605-91-7$ & 4.97 & $151 ; 152 ; 222 ; 224$ \\
\hline 31 & 2,4',5-Trichlorobiphenyl & $16606-02-3$ & 5.67 & $186 ; 256 ; 258 ; 260$ \\
\hline 47 & 2,2',4,4'-Tetrachlorobiphenyl & $2437-79-8$ & 5.85 & $220 ; 290 ; 292 ; 294$ \\
\hline 91 & 2,2',3,4',6-Pentachlorobiphenyl & $68194-05-8$ & 6.13 & $254 ; 256 ; \mathbf{3 2 6} ; 328$ \\
\hline 154 & $\begin{array}{l}2,2^{\prime}, 4,4^{\prime}, 5,6^{\prime}-\text { Hexachlorobiphe- } \\
\text { nyl }\end{array}$ & $60145-22-4$ & 6.76 & $290 ; 358 ; \mathbf{3 6 0} ; 361$ \\
\hline 171 & $\begin{array}{l}2,2^{\prime}, 3,3^{\prime}, 4,4^{\prime}, 6-H e p t a c h l o r o b i- \\
\text { phenyl }\end{array}$ & $52663-71-5$ & 7.11 & $323 ; \mathbf{3 9 4} ; 396 ; 398$ \\
\hline 200 & $\begin{array}{l}2,2^{\prime}, 3,3^{\prime}, 4,5,6,6^{\prime} \text {-Octachlorobi- } \\
\text { phenyl }\end{array}$ & $52663-73-7$ & 7.27 & $358 ; 428 ; \mathbf{4 3 0} ; 432$ \\
\hline
\end{tabular}

* from Hawker and Conwell, 1988 [12]; $\uparrow:$ Bold $\mathrm{m} / \mathrm{z}$ employed for quantification 


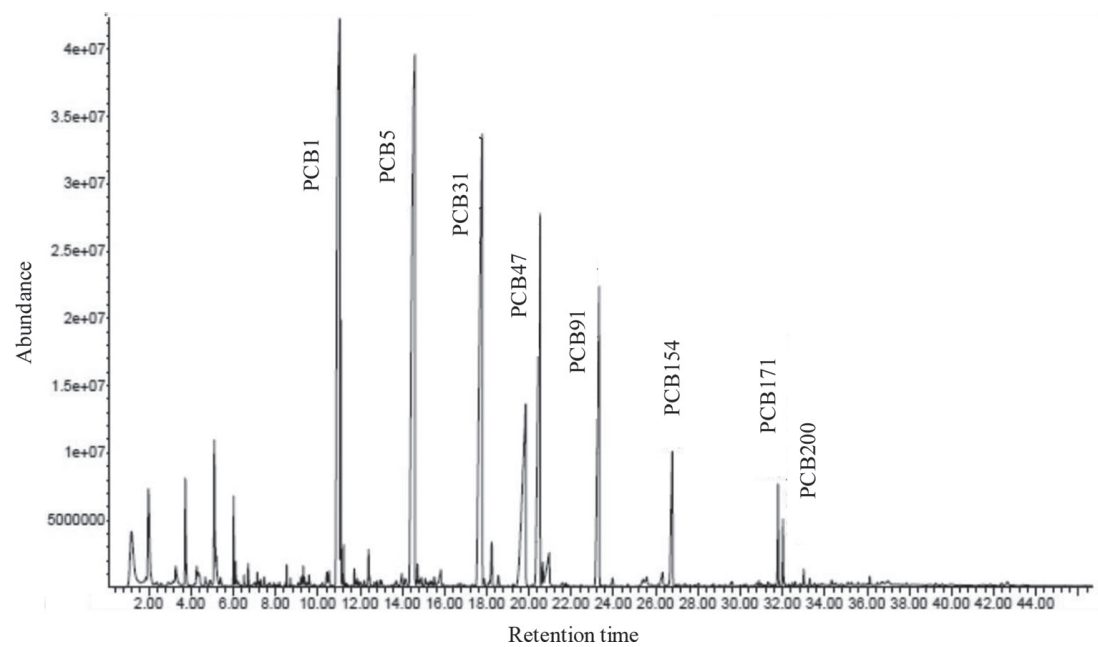

Figure 1: Total ion chromatogram of 8 PCB congeners standard mix in a $100 \mathrm{ppb}$ TUE solution.

efficiency without this salt. The values for the lipophilic octanol/water partition coefficients $\left(\log K_{o w}\right)$ for all the PCB congeners, always higher than 4.46, could avoid the need of $\mathrm{NaCl}$ addition, mainly targeted for solutes with low and medium $\log K_{o w}(<4.0)$ [14]. For that reason, the SBSE extraction procedure was carried out without salt addition.

According to $\mathrm{pH}$, it is an important variable for analytes with acidic or basic properties [15], being adjusted to get the non-ionic form of the compound which leads to a better extraction efficiency. Because treated urban effluents (TUE) from the wastewater treatment plant (WWTP) used in this study were nor too acidic $(\mathrm{pH}<2)$ nor too basic $(\mathrm{pH}>9), \mathrm{pH}$ conditions were not modified, in order to minimize sample manipulation.

Finally, the extraction time was also studied, although only in one of the microbeads, i.e. MP-A. In order to get the optimum equilibration time, analyses were developed after $2,4,8$, and $24 \mathrm{~h}$, using the major ion for each PCB congener's quantification, as reported in Table 1. The extraction time profiles for MP-A are depicted in Figure 2.

\subsection{PCB congeners extraction in TUE}

After a previous characterization of sorption properties for PCB congeners in microbeads dispersed in bi-distilled water [8], studies were eventually carried out in treated urban effluents (TUE), in order to assess the PCB sorption capacity on microbeads after their use in personal care products, and their disposal in wastewater.

The recovery of PCB congeners by microbeads was different depending on the microbead type considered, as depicted in Figure 3. There was a higher amount of PCB congeners collected by microbeads in bi-distilled water than in TUE, except for MP-A. This result could be attributed to a synergistic effect of organic matter [16], competing with microbeads for the sorption of PCB congeners and reducing the number of surface accessible sites onto the microplastic.

Microbead Type A (MP-A) proved to recover the maximum amount of PCB congeners, both in bi-distilled water and TUE, as depicted in Figures 3 and 4. This MP-A appeared to be 


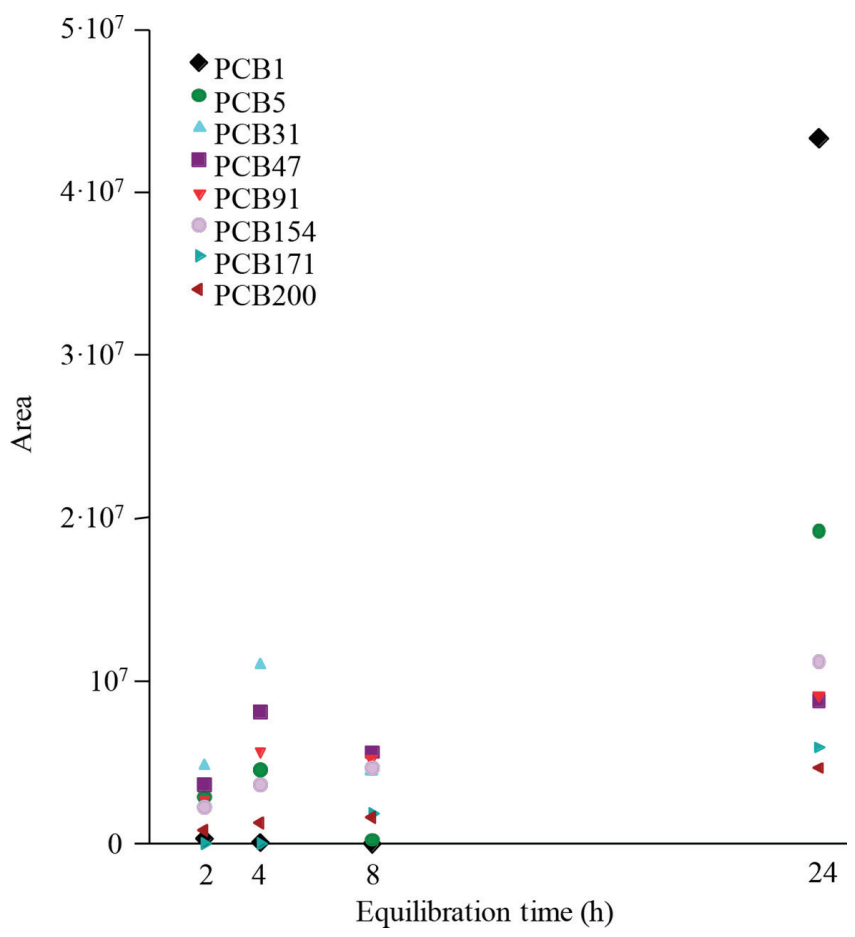

Figure 2: Extraction time profiles for PCB congeners in Microbeads Type A (MP-A).

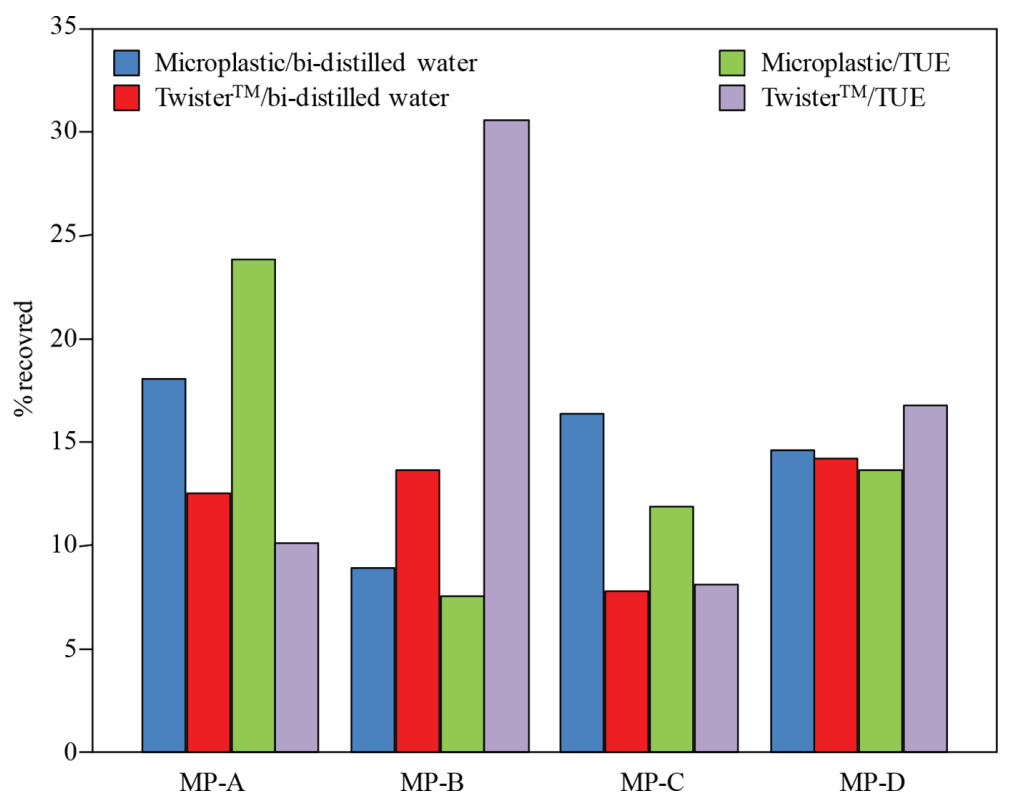

Figure 3: Percentage of total PCB congeners recovered by microbeads and stir bars (Twister ${ }^{\mathrm{TM}}$ ), as measured in bi-distilled water and TUE (Treated Urban Effluents). 


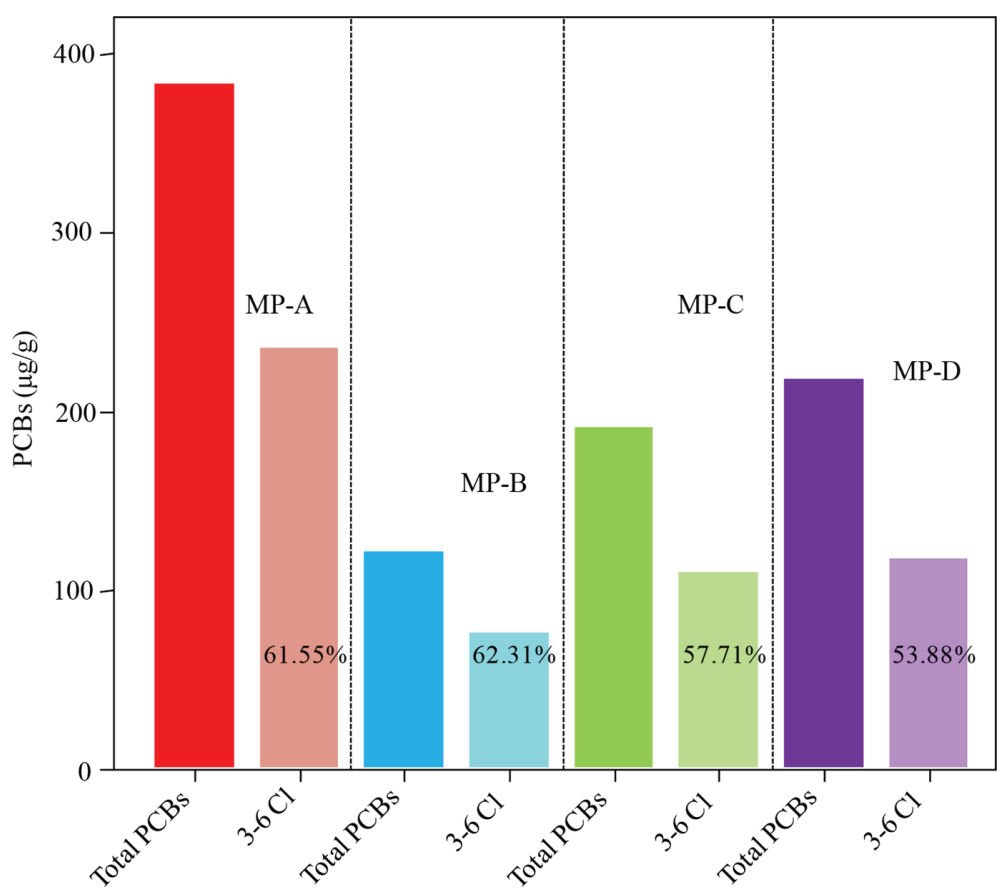

Figure 4: Total amount of PCB congeners recovered by each type of microbead analyzed, compared to sorption of $\mathrm{PCB}$ congeners with three to six Cl-substitutions, i.e. PCB31, PCB47, PCB91, and PCB154.

the microplastic with the highest specific surface area, i.e. $4.776 \pm 2.151 \mathrm{~m}^{2} / \mathrm{g}$, as determined in previous studies [8]. Besides this fact, the commercial facial cleanser containing these microbeads had titanium dioxide $\left(\mathrm{TiO}_{2}\right)$ in its composition. This white pigment acts as a blocker for Sun harmful radiations, i.e. ultraviolet rays, which lead to sunburn, accelerate ageing of the skin giving rise to wrinkles, and increase skin cancer risk [17]. In any case, titanium dioxide could have also been added as a nanomaterial during the plastic formulation as an UV blocker [18].

Conversely, MP-B, with oxidized polyethylene in its constitution and, therefore, with a polar composition to a greater extent, proved to have the lowest sorption capacity (Figs 3 and 4), despite a specific surface area similar to MP-C and MP-D. This fact would imply partitioning into the polymer as a possible transport mechanism. When the extraction pattern was analyzed according to $\mathrm{PCB}$ congeners with three to six Cl-substitutions, MP-B displayed the highest sorption percentage $(62.31 \%)$, similar to that achieved by MP-A $(61.55 \%)$, the microbeads with titanium dioxide $\left(\mathrm{TiO}_{2}\right)$ in the commercial composition and the greatest specific surface area, and higher than for MP-C (57.71\%) and MP-D (53.88\%). This comparison was carried out because the tri- to hexa-PCB congener mixture was the commercial product mainly used before they were banned by the electric industry, as reported by Cailleaud et al. [19], and produced in the USA, France, Germany, Italy, Spain, former Czechoslovakia, Poland, former USSR and Japan [10]. The sorption percentage of each PCB congener, and subsequently the amount being transported in each microbead, is an important issue because there is a different rate of metabolism in living organisms, depending on the 
degree of ring chlorination and the substitution pattern within the rings, among others [20]. Figure 5 displays the sorption pattern of the eight PCB congeners extracted from TUE with microbeads and in stir bars (Twister ${ }^{\mathrm{TM}}$ ), included in the TUE after the microbead extraction was completed, with a statistically significant inverse correlation $(r=-0.701, p<0.001)$.

It can be observed that PCB1 and PCB5, the less substituted congeners, with low $\log K_{\text {ow }}$ values and high hydrophilicity, mainly remained in water, being poorly transported by the four types of microplastics considered in this study but recovered by means of Twister $^{\mathrm{TM}}$ (Fig. 5b).

However, PCB congeners with 3, 4, 5, 6, 7, and 8 chlorine substitution proved to be well carried out with the microbeads, specially with MP-A, MP-C, and MP-D, and in a lower extent with MP-B, the oxidized polyethylene (Fig. 5a). In general, the higher the chlorine content of a PCB congener, the less the biodegradability, being congeners with more than five chlorine substitution practically recalcitrant to aerobic metabolism [21], although some microorganisms have been reported to transform up to hexachlorobiphenyls [22]. Congeners PCB1 and PCB5, besides having only one and two chlorine atoms, respectively, all of them are on a single ring, being biodegraded faster than those containing the same number on both rings [23]. Moreover, scientists have only been able to isolate aerobic bacteria growing on monochlorobiphenyls as a sole source of carbon [24].

All these results suggest that PCB congeners, as chemical pollutants of wastewater effluents, can be sorbed on microbeads from personal care products, especially for congeners with more than three chlorine substitutions. This fact could enhance the distribution and movement of these pollutants through the food chain after microbeads are ingested by living organisms, being accumulated in different tissues. The bioavailability of these pollutants, once they reach the target organism, depends on partitioning limitations from the microplastics [25] and their ability to be metabolized by the organism [26].

Braekevelt et al. [27], in their study on the behavior of PCB and BDE (brominated diphenyl ether) congeners according to their octanol-water partition coefficients $\left(\log K_{o w}\right)$, reported that tri- to tetra-congeners would pose the highest bioaccumulation risk, being higher congeners too non-polar to be bioaccumulated. Wingfors et al. [26] indicated that PCB congeners with vicinal hydrogens in meta-para positions would be easily metabolized, i.e., in our study: PCB1, PCB5, PCB31, PCB91, and PCB200, being PCB47 (tetra-chlorinated), PCB154 (hexa-chlorinated), and $\mathrm{PCB} 171$ (hepta-chlorinated) very persistent congeners. Among these last very persistent PCB congeners, PCB47 and PCB171 belong to group II [28], which
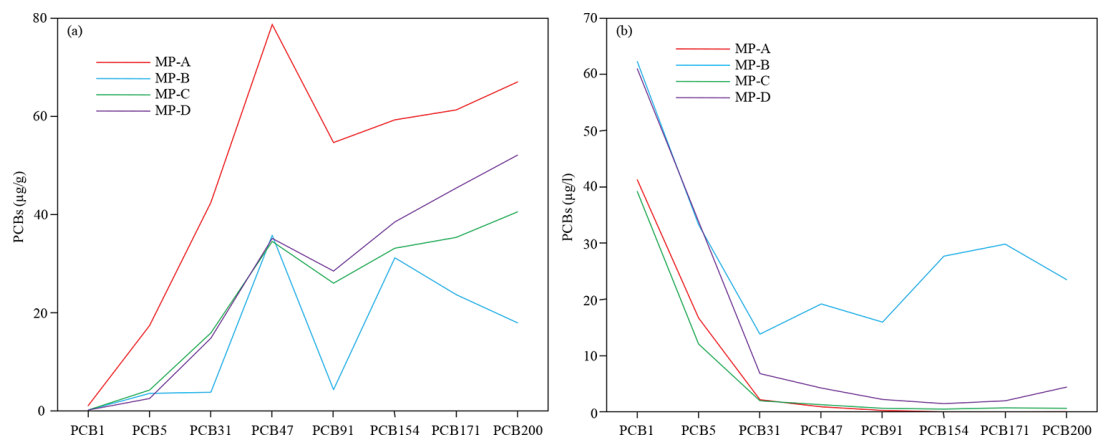

Figure 5: PCB congeners recovered in TUE by each type of microbead: (a) retained by the microbead $(\mu \mathrm{g} / \mathrm{g})$, and (b) concentration in the remaining water as adsorbed by Twister $^{\mathrm{TM}}$. 

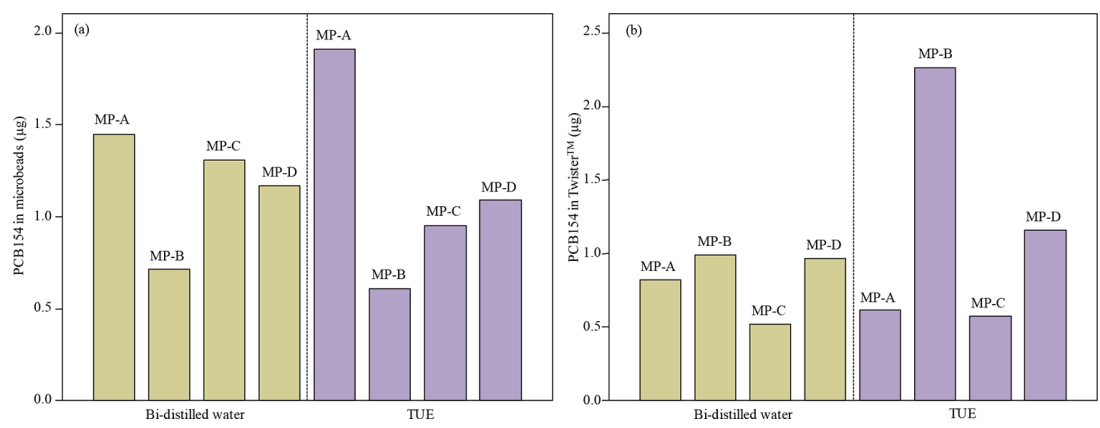

Figure 6: Recovery of PCB154 by (a) microbeads, and (b) Twister ${ }^{\mathrm{TM}}$, both in bi-distilled water and treated urban effluents.

includes PCB congeners with vicinal $\mathrm{H}$-atoms only in ortho-meta positions, and, at least, diortho Cl-substitution. Despite the inhibition of their metabolism because of the steric hindrance of the ortho-substituents, PCB154 appears to be a more recalcitrant congener, belonging to group I with no vicinal $\mathrm{H}$-atoms.

For those reasons, the PCB154 recovery pattern in microbeads and Twister $^{\mathrm{TM}}$ was calculated, both in bi-distilled water and effluent from the wastewater treatment plant (TUE), as depicted in Figure 6. Again, MP-A was the microplastic that accumulated this PCB congener in a higher extent, especially in TUE samples, and MP-B, with low affinity for more substituted PCB congeners because of a less lipophilic composition with oxidized polyethylene, remained as the less polluted according PCB154 (Fig. 6a). On the contrary, results on Twist$\mathrm{er}^{\mathrm{TM}}$ were different but not statistically significant $(p>0.05)$, with a maximum amount of PCB154 recovered by Twister ${ }^{\mathrm{TM}}$ on TUE from MP-B.

\section{CONCLUSIONS}

This paper presents realistic evidence that microplastics included in personal care products may act as a carrier for persistent organic pollutants, i.e., PCB congeners. The hydrophobic composition of these pollutants, with high $\log K_{o w}$ coefficients, would make them to be sorbed by polyethylene. MP-A, with the highest specific surface area, proved to recover the maximum amount of PCB congeners, also presenting titanium dioxide as an extra ingredient; and MP-B, with oxidized polyethylene in its composition, had the lowest sorption capacity, despite a surface area similar to MP-C and MP-D. The less substituted congeners, i.e., PCB1 and PCB5 were the only ones poorly transported by microplastics, displaying MP-B the highest sorption percentage for three to six Cl-substituted congeners, those commercially more used before they were banned.

\section{ACKNOWLEDGEMENTS}

Analyses carried out by M. Guillén and M.J. Roca were supported by a UPCT fellowship (Project 30.05.21.7312). The authors would like to extend their thanks to crew from wastewater treatment plant of Cartagena 'Cabezo Beaza' for their assistance with sample collection.

\section{REFERENCES}

[1] Plastics - the Facts 2016. An analysis of European plastics production, demand and waste data. Available at: www.plasticseurope.org/documents/20161014113313plastics_the_facts_2016_final_version.pdf. (Accessed 20 April 2017). 
[2] Rocha-Santos, T. \& Duarte, A.C., A critical overview of the analytical approaches to the occurrence, the fate and the behavior of microplastics in the environment. TrAC Trends in Analytical Chemistry, 65, pp. 47-53, 2015. https://doi.org/10.1016/j.trac.2014.10.011

[3] Li, W.C., Tse, H.F. \& Fok, L., Plastic waste in the marine environment: A review of sources, occurrence and effects. Science of the Total Environment, 566-567, pp. 333-349, 2016.

https://doi.org/10.1016/j.scitotenv.2016.05.084

[4] Galgani, F., Hanke, G., Werner, S., Oosterbaan, L., Nilsson, P., Fleet, D., Kinsey, S., Thompson, R.C., van Franeker, J., Vlachogianni, T., Scoullos, M., Veiga, J.M., Palatinus, A., Matiddi, M., Maes, T., Korpinen, S., Budziak, A., Leslie, H., Gago, J. \& Liebezeit, G., Guidance on Monitoring for Marine Litter in European Seas. MSFD Technical Subgroup on Marine Litter (TSG-ML). European Commission, Joint Research Centre Scientific and Policy, Institute for Environment and Sustainability Reports, 2013.

[5] Bayo, J., Olmos, S., López-Castellanos, J. \& Alcolea, A., Microplastics and microfibers in the sludge of a municipal wastewater treatment plant. International Journal of Sustainable Development and Planning, 11(5), pp. 812-821, 2016. https://doi.org/10.2495/sdp-v11-n5-812-821

[6] Holmes, L.A., Turner, A. \& Thompson, R.C., Adsorption of trace metals to plastic resin pellets in the marine environment. Environmental Pollution, 160, pp. 42-48, 2012. https://doi.org/10.1016/j.envpol.2011.08.052

[7] Napper, I.E., Bakir, A., Rowland, S.J. \& Thompson, R.C., Characterisation, quantity and sorptive properties of microplastics extracted from cosmetics, Marine Pollution Bulletin, 99(1), pp. 178-185, 2015.

https://doi.org/10.1016/j.marpolbul.2015.07.029

[8] Bayo, J., Martínez, A., Guillén, M., Olmos, S., Roca, M.J. \& Alcolea, A., Microbeads in commercial facial cleansers: threatening the environment. Clean - Soil, Air, Water, 45(6), 2017.

https://doi.org/10.1002/clen.201600163

[9] Rios, L.M., Moore, C. \& Jones, P.R., Persistent organic pollutants carried by synthetic polymers in the ocean environment. Marine Pollution Bulletin, 54(8), pp. 1230-1237, 2007. https://doi.org/10.1016/j.marpolbul.2007.03.022

[10] Giesy, J.P. \& Kannan, K., Dioxin-like and non-dioxin-like toxic effects of polychlorinated biphenyls (PCBs): implications for risk assessment. Critical Reviews in Toxicology, 28(6), pp. 511-569, 1998.

https://doi.org/10.1080/10408449891344263

[11] Ballschmiter, K. \& Zell, M., Analysis of polychlorinated biphenyls (PCB) by glass capillary gas chromatography. Composition of technical Aroclor and Clophen-PCB mixtures. Fresenius' Zeitschrift für Analytische Chemie, 302(1), pp. 20-31, 1980. https://doi.org/10.1007/bf00469758

[12] Hawker, D.W. \& Connell, D.W. Octanol-water partition coefficients of polychlorinated biphenyl congeners. Environmental Science \& Technology, 22(4), pp. 382-387, 1988. https://doi.org/10.1021/es00169a004

[13] Rodil, R. \& Moeder, M., Development of a method for the determination of UV filters in water samples using stir bar sorptive extraction and thermal desorption-gas chromatography-mass spectrometry. Journal of Chromatography A, 1179(2), pp. 81-88, 2008. https://doi.org/10.1016/j.chroma.2007.11.090 
[14] Tölgyessy, P., Vrana, B. \& Krascsenits, Z., Development of a screening method for the analysis of organic pollutants in water using dual stir bar sorptive extraction-thermal desorption-gas chromatography-mass spectrometry. Talanta, 87, pp. 152-160, 2011. https://doi.org/10.1016/j.talanta.2011.09.055

[15] Prieto, A., Basauri, O., Rodil, R., Usobiaga, A., Fernández, L.A., Etxebarria, N. \& Zuloaga, O., Stir-bar sorptive extraction: a view on method optimisation, novel applications, limitations and potential solutions. Journal of Chromatography A, 1217, pp. 2642-2666, 2010.

https://doi.org/10.1016/j.chroma.2009.12.051

[16] Koelmans, A.A., Meulman, B., Meijer, T. \& Jonker, M. T., Attenuation of polychlorinated biphenyl sorption to charcoal by humic acids. Environmental Science \& Technology, 43(3), pp. 736-742, 2009. https://doi.org/10.1021/es802862b

[17] Landsiedel, R., Ma-Hock, L., Van Ravenzwaay, B., Schulz, M., Wiench, K., Champ, S., Schulte, S., Wohlleben, W. \& Oesch, F., Gene toxicity studies on titanium dioxide and zinc oxide nanomaterials used for UV-protection in cosmetic formulations. Nanotoxicology, 4(4), pp. 364-381, 2010. https://doi.org/10.3109/17435390.2010.506694

[18] Rocha-Santos, T. \& Duarte, A.C., A critical overview of the analytical approaches to the occurrence, the fate and the behavior of microplastics in the environment. TrAC Trends in Analytical Chemistry, 65, pp. 47-53, 2015. https://doi.org/10.1016/j.trac.2014.10.011

[19] Cailleaud, K., Forget-Leray, J., Souissi, S., Hilde, D., LeMenach, K. \& Budzinski, H., Seasonal variations of hydrophobic organic contaminant concentrations in the watercolumn of the Seine Estuary and their transfer to a planktonic species Eurytemora affinis (Calanoida, copepoda). Part 1: PCBs and PAHs. Chemosphere, 70(2), pp. 270-280, 2007. https://doi.org/10.1016/j.chemosphere.2007.05.095

[20] Safe, S., Toxicology, structure-function relationship, and human and environmental health impacts of polychlorinated biphenyls: progress and problems. Environmental Health Perspectives, 100, pp. 259-268, 1993. https://doi.org/10.2307/3431532

[21] Adebusoye, S.A., Ilori, M.O., Picardal, F.W. \& Amund, O.O., Metabolism of chlorinated biphenyls: Use of 3, 3'-and 3, 5-dichlorobiphenyl as sole sources of carbon by natural species of Ralstonia and Pseudomonas. Chemosphere, 70(4), pp. 656-663, 2008. https://doi.org/10.1016/j.chemosphere.2007.06.079

[22] Seto, M., Kimbara, K., Shimura, M., Hatta, T., Fukuda, M. \& Yano, K., A novel transformation of polychlorinated biphenyls by Rhodococcus sp. strain RHA1. Applied and Environmental Microbiology, 61(9), pp. 3353-3358, 1995.

[23] Furukawa, K., Matsumura, F. \& Tonomura, K., Alcaligenes and Acinetobacter strains capable of degrading polychlorinated biphenyls. Agricultural and Biological Chemistry, 42(3), pp. 543-548, 1978. https://doi.org/10.1271/bbb1961.42.543

[24] Pieper, D.H., Aerobic degradation of polychlorinated biphenyls. Applied Microbiology and Biotechnology, 67(2), pp. 170-191, 2005. https://doi.org/10.1007/s00253-004-1810-4 
[25] Wardrop, P., Shimeta, J., Nugegoda, D., Morrison, P.D., Miranda, A., Tang, M. \& Clarke, B.O., Chemical pollutants sorbed to ingested microbeads from personal care products accumulate in fish. Environmental Science \& Technology, 50(7), pp. 4037-4044, 2016.

https://doi.org/10.1021/acs.est.5b06280

[26] Wingfors, H., Seldén, A.I., Nilsson, C. \& Haglund, P., Identification of markers for PCB exposure in plasma from Swedish construction workers removing old elastic sealants. Annals of Occupational Hygiene, 50(1), pp. 65-73, 2006.

https://doi.org/10.1093/annhyg/mei063

[27] Braekevelt, E., Tittlemier, S.A. \& Tomy, G.T., Direct measurement of octanol-water partition coefficients of some environmentally relevant brominated diphenyl ether congeners. Chemosphere, 51(7), pp. 563-567, 2003. https://doi.org/10.1016/s0045-6535(02)00841-x

[28] Borgå, K., Wolkers, H., Skaare, J.U., Hop, H., Muir, D.C. \& Gabrielsen, G.W., Bioaccumulation of PCBs in Arctic seabirds: influence of dietary exposure and congener biotransformation. Environmental Pollution, 134(3), pp. 397-409, 2005.

https://doi.org/10.1016/j.envpol.2004.09.016 